\title{
MEMBANGUN MODEL KADAR HEMOGLOBIN (Hb) PENDERITA POLISITEMIA VERA YANG MEMPERTIMBANGKAN MOOD SWINGS DENGAN METODE PENCOCOKAN KURVA
}

\author{
R. Fadilah¹, R. Ratianingsih², A. I. Jaya ${ }^{3}$ \\ 1,2,3Program Studi Matematika Jurusan Matematika FMIPA Universitas Tadulako \\ Jalan Soekarno-Hatta Km. 09 Tondo, Palu 94118, Indonesia. \\ 11rezyfadilah@gmail.com, 2,3ratianingsih@yahoo.com
}

\begin{abstract}
Hematology routine checkup has an important role in the diagnosis of polisitemia vera (PV) disease. Disordered checkup will cause the continuation of disease because the doctor did not have sufficient data to diagnose the progress of a disease. This research reviews the mood changes of the PV patient as external influences of a differential equation with a variable bound in the form of levels of hemoglobin patient, where the PV patient did not have some laboratorium datas of hemoglobin levels at a certain time. Differential equation as a construct model is adapted from spring mass system, whereas external influences found from the laboratorium data of PV patient use curve fitting that is cubic spline interpolation method. The result of the research shows that the accuration of model solution of hemoglobin levels of PV patient is $\frac{d^{2} R}{d t^{2}}+\beta \cdot \frac{d R}{d t}+\omega^{2} \cdot R(t)=0.75 \sin 0.35 \pi t+u(t)$, from the laboratorium data of PV patient at 10 data points. There are also 9 data points that can not be predicted appropriate but is having the highest relative errors of $7.35294 \times 10^{-8}$.
\end{abstract}

Keywords : Cubic Spline, Curve Fitting, Hemoglobin, Polisitemia Vera

\section{ABSTRAK}

Pemeriksaan hematologi rutin memiliki peran penting dalam mendiagnosa penyakit polisitemia vera (PV). Pemeriksaan yang tidak teratur akan berdampak pada keberlanjutan diagnosa penyakit ini, karena dokter tidak memiliki data yang cukup untuk mendiagnosa perkembangan penyakit. Penelitian ini meninjau perubahan mood penderita PV sebagai pengaruh eksternal dari suatu persamaan differensial dengan variabel terikat berupa kadar hemoglobin penderita PV, dimana penderita PV tidak memiliki beberapa data pengukuran laboratorium dari kadar hemoglobin pada sejumlah waktu. Persamaan differensial pembangun model tersebut diadaptasi dari sistem pegas massa, sedangkan pengaruh eksternal diperoleh dari data laboratorium penderita PV dengan menggunakan pencocokan kurva yaitu metode interpolasi spline kubik. Hasil penelitian menunjukkan adanya ketepatan solusi model kadar hemoglobin penderita PV yang dibangun, yaitu $\frac{d^{2} R}{d t^{2}}+\beta \cdot \frac{d R}{d t}+\omega^{2} \cdot R(t)=$ $0.75 \sin 0.35 \pi t+u(t)$, dengan data pengukuran Laboratorium kadar hemoglobin penderita 
PV di 10 titik. Terdapat pula 9 titik data yang tidak dapat diprediksi dengan tepat namun memiliki kesalahan relatif tertinggi sebesar $7.35294 \times 10^{-8}$.

\section{Kata Kunci $\quad$ : Hemoglobin, Pencocokan Kurva, Polisitemia Vera, Spline Kubik}

\section{PENDAHULUAN}

Polisitemia merupakan suatu penyakit dengan keadaan hypervolemia, adanya hyperplasia sel-sel hemopolitik dan peningkatan jumlah eritrosit. [3] Polisitemia juga dapat dikatakan sebagai kondisi yang jarang terjadi dimana produksi sel darah merah oleh sumsum tulang berlebihan. Polisitemia terbagi atas dua jenis utama, yaitu polisitemia primer (polisitemia vera) dan polisitemia sekunder. Keduanya memiliki penyebab, gejala, dan perawatan yang berbeda. Jika dibandingkan dengan polisitemia sekunder, polisitemia vera yang selanjutnya disingkat PV ini memiliki kondisi yang lebih serius dan dapat mengakibatkan komplikasi kritis, dimana terjadi penebalan darah sehingga menghasilkan terlalu banyak sel darah merah. [4]

Pada kasus PV, ada beberapa faktor penting yang perlu diperhatikan saat pemeriksaan hematologi, salah satunya adalah kadar hemoglobin. Seseorang yang menderita PV menunjukkan kadar hemoglobin $(\mathrm{Hb})$ melampaui batas normal. Agar keadaan kadar hemoglobin tidak mengalami perubahan yang cukup tinggi, salah satunya adalah mengatur perubahan suasana hati (mood swings). Pengukuran laboratorium kadar hemoglobin sangat dibutuhkan dokter dalam mendiagnosa penyakit PV. Jika pemeriksaan hematologi tidak teratur, dimana terdapat data pengukuran kadar hemoglobin yang tidak dimiliki, dokter akan menemui kesulitan dalam diagnosa lanjut perkembangan penyakit PV.

Penelitian ini akan meninjau perubahan mood penderita PV sebagai pengaruh eksternal dari suatu persamaan differensial dengan variabel terikat berupa kadar hemoglobin penderita PV dari hasil pengukuran laboratorium. Dimana persamaan differensial yang dibangun tersebut diadaptasi dari sistem pegas massa dengan redaman. Selanjutnya solusi model tersebut merepresentasikan kadar hemoglobin penderita PV di setiap waktu. Ketepatan solusi akan diverifikasi dengan pencocokan kurva dari data pengukuran laboratorium kadar hemoglobin penderita PV, dengan ketepatan solusi inilah diharapkan nantinya tidak ditemui kesulitan untuk melakukan diagnosa lanjut terhadap penderita PV walau dalam keadaan pemeriksaan hematologi terhadap penderita tidak teratur.

\section{METODE PENELITIAN}

Penelitian ini bersifat kajian kuantitatif terhadap persamaan differensial orde dua tak homogen dengan menggunakan metode pencocokan kurva dengan interpolasi spline kubik. Data yang digunakan berupa nilai-nilai parameter yaitu perubahan kadar estrogen per hari $\beta$ dan kadar 
serotonin per hari $\omega^{2}$, dan variabel yang diperlukan berupa waktu $(t)$ sebagai variabel bebas dan hemoglobin $R(t)$ sebagai variabel terikatnya. Adapun proses dalam membangun model dalam penelitian ini ialah sebagai berikut:

1. Mengambil data kadar hemoglobin penderita PV

2. Membangun model kadar hemoglobin penderita PV

3. Menentukan solusi model

4. Pencocokan kurva

5. Membandingkan solusi model dengan hasil pencocokan kurva

\section{HASIL DAN PEMBAHASAN}

Model matematika kadar hemoglobin penderita PV yang dibangun dalam penelitian ini mempertimbangkan pengaruh eksternal berupa perubahan mood penderitanya. Model tersebut berupa persamaan differensial dengan variabel bebas berupa waktu $(t)$ dan variabel terikat berupa kadar hemoglobin $R(t)$. Data pengukuran laboratorium kadar hemoglobin penderita PV digunakan sebagai fungsi eksternal yang bekerja pada persamaan differensial. Data tersebut diolah dengan menggunakan pencocokan kurva, dalam hal ini digunakan metode interpolasi spline kubik.

Model matematika kadar hemoglobin berbentuk persamaan differensial orde dua tak homogen yang diadaptasi dari sistem pegas massa. Bentuk persamaan yang diadaptasi dari sistem pegas massa dengan karakter koleris dinyatakan dalam persamaan (1) dan (2) sebagai berikut:

$$
\begin{aligned}
& \frac{d^{2} R}{d t^{2}}+\beta \cdot \frac{d R}{d t}+\omega^{2} \cdot R(t)=f(t) \\
& f(t)=0.75 \sin 0.35 \pi t+u(t)
\end{aligned}
$$

Adapun nilai kadar estrogen $(\beta)$ dan kadar serotonin $\left(\omega^{2}\right)$ dalam darah penderita PV dengan karakter koleris adalah $\beta=0.5$ dan $\omega^{2}=2$. [2] Adapun fungsi eksternal $u(t)$ yang dibangun dari data pengukuran laboratorium kadar hemoglobin penderita PV dengan metode spline kubik. Data pengukuran laboratorium kadar hemoglobin penderita PV dengan menggunakan program Maple 13 dapat diplot sebagai berikut: 


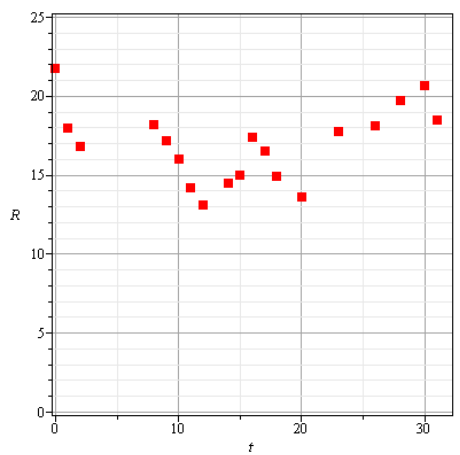

Gambar 1: Plot data pengukuran laboratorium kadar hemoglobin

Selanjutnya dalam interpolasi dengan metode interpolasi spline kubik adalah membagi bentuk kurva tersebut menjadi beberapa bagian yang kemudian disebut sebagai segementasi kurva.

Data pada Gambar 1. disegmentasi menjadi empat interval yaitu interval I $=[0,8]$, interval II $=$ $[8,15]$, interval III $=[15,20]$, dan interval IV $=[20,31]$ untuk ditentukan persamaan grafik yang merepresentasikannya. Setiap segmen kurva di atas didefinisikan dari polinomial terpisah yang berlaku pada setiap intervalnya. Segmentasi yang dilakukan dengan memilih bentuk kurva parabolik di setiap interval, yang kemudian digabungkan menjadi satu dan membentuk suatu kurva polinomial utuh yang kontinu. Sehingga kurva hasil segmentasi di atas tersambung mulus dan tidak terputus. Adapun plot segmentasi yang dilakukan adalah sebagai berikut:

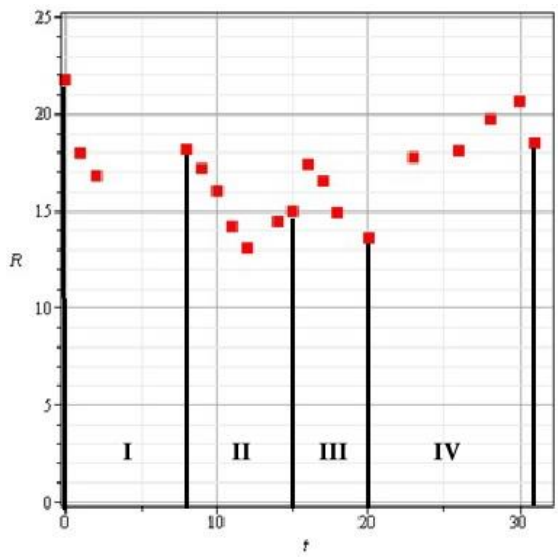

Gambar 2: Plot data yang disegmentasi menjadi empat interval

Berdasarkan hasil pencocokan kurva pada empat interval, model kadar hemoglobin dapat dinyatakan sebagai berikut:

$$
\frac{d^{2} R}{d t^{2}}+\beta \cdot \frac{d R}{d t}+\omega^{2} \cdot R(t)=0.75 \sin 0.35 \pi t+u(t)
$$

dengan: 


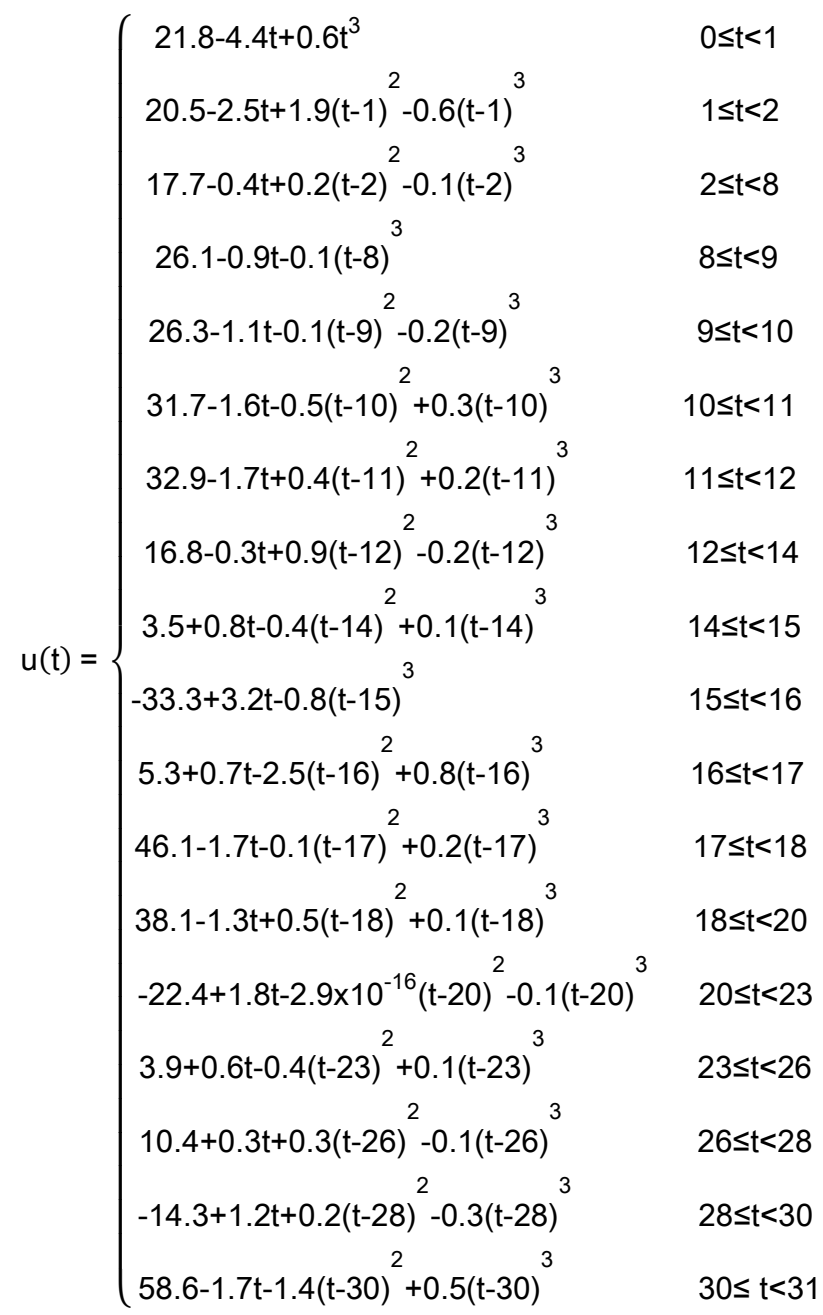

Solusi model dari persamaan (3) diperoleh dengan menentukan solusi homogen dan solusi partikular di masing-masing interval. Selanjutnya, solusi umum dari model diperoleh dengan menjumlahkan solusi homogen dan solusi partikular.

Solusi khusus diperoleh dengan memasukkan nilai batas di setiap titik sesuai intervalnya, sehingga diperoleh konstanta dari model yang dibangun pada masing-masing titik, yaitu $R(0)=$ $21.80000000, R(1)=18.00000000, R(2)=16.80000001, R(3)=16.50000000, R(4)=16.50000000$, $R(5)=16.70000000, \quad R(6)=17.10000000, \quad R(7)=17.60000000, \quad R(8)=18.19999999, \quad R(9)=$ $17.20000001, \quad R(10)=16.00000000, \quad R(11)=14.19999999, \quad R(12)=13.10000000, \quad R(13)=$ $13.50000000, \quad R(14)=14.50000000, \quad R(15)=15.00000000, \quad R(16)=17.39999998, \quad R(17)=$ $16.50000000, \quad R(18)=14.90000001, \quad R(19)=14.01000000, \quad R(20)=13.59999999, \quad R(21)=$ $15.30000001, \quad R(22)=16.79999999, \quad R(23)=17.80000000, \quad R(24)=18.10000001, \quad R(25)=$ 
$18.00000000, \quad R(26)=18.10000000, \quad R(27)=18.70000000, \quad R(28)=19.70000001, \quad R(29)=$ $20.80000001, R(30)=20.69999999, R(31)=18.50000000$.

Representasi dari model kadar hemoglobin penderita PV, diperoleh dari nilai solusi model kadar hemoglobin penderita PV dalam rentang $0 \leq t<31$ pada masing-masing solusi khusus. Akurasi model tersebut selanjutnya diukur melalui ketepatan solusi model dalam memprediksi hasil pengukuran laboratorium kadar hemoglobin penderita PV untuk waktu yang bersesuaian. Adapun perbandingan data hasil pengukuran laboratorium dan model dapat dilihat pada Gambar 3.

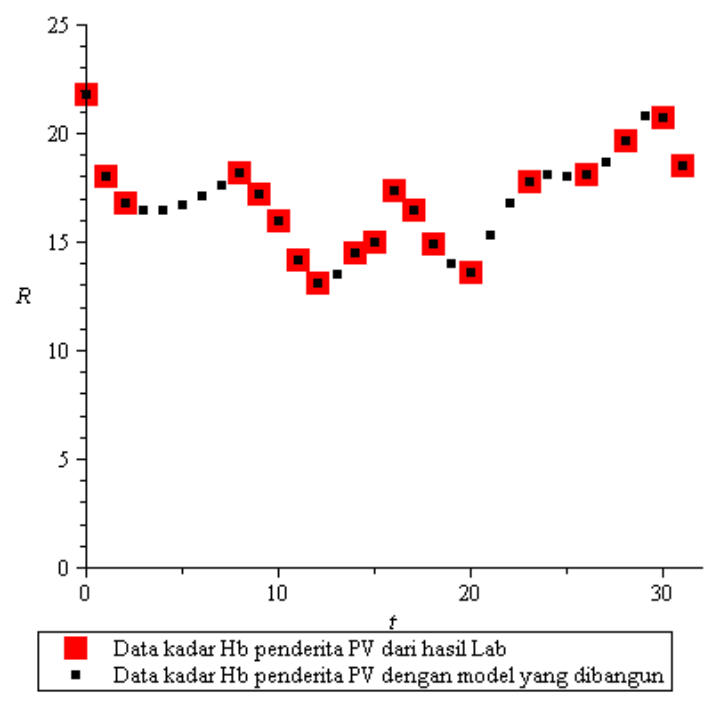

Gambar 3: Plot perbandingan antara data hasil pengukuran laboratorium kadar hemoglobin penderita PV dan model kadar hemoglobin yang dibangun

Ketepatan solusi model kadar hemoglobin penderita PV yang dibangun dengan meninjau perubahan mood penderita PV yang berkarakter koleris sebagai pengaruh eksternalnya, selanjutnya solusi model diverifikasi dengan membandingkan data pengukuran laboratorium kadar hemoglobin penderita PV untuk waktu yang bersesuaian. Selisih dari keduanya mencerminkan ketidaktepatan model dalam memprediksi kadar hemoglobin penderita PV namun dengan kesalahan yang relatif kecil. Ketidaktepatan tersebut dapat dilihat dari galat relatifnya yang menunjukkan kesalahan sangat kecil. Ketidaktepatan tersebut dinyatakan dalam Tabel 1. 
Tabel 1: Tabel Nilai Kadar Hemoglobin dari Pengukuran dan Solusi Model

\begin{tabular}{|c|c|c|c|}
\hline $\begin{array}{l}\text { Waktu } \\
\text { (Pengukuran } \\
\text { ke-) } \\
\text { (1) }\end{array}$ & $\begin{array}{l}\text { Kadar } \mathrm{Hb} \text { dari Hasil } \\
\text { Pengukuran Laboratorium } \\
\text { (g/dL) } \\
(2)\end{array}$ & $\begin{array}{l}\text { Kadar Hb dari Hasil } \\
\text { Solusi Model } \\
\text { (g/dL) } \\
\text { (3) }\end{array}$ & $\begin{array}{l}\text { Galat } \\
\text { Relatif } \\
(\%) \\
(4)\end{array}$ \\
\hline 0 & 21.8 & 21.80000000 & 0 \\
\hline 1 & 18.0 & 18.00000000 & 0 \\
\hline 2 & 16.8 & 16.80000001 & $5.95238 \times 10^{-8}$ \\
\hline 3 & - & 16.50000000 & - \\
\hline 4 & - & 16.50000000 & - \\
\hline 5 & - & 16.70000000 & - \\
\hline 6 & - & 17.10000000 & - \\
\hline 7 & - & 17.60000000 & - \\
\hline 8 & 18.2 & 18.19999999 & $5.49451 \times 10^{-8}$ \\
\hline 9 & 17.2 & 17.20000001 & $5.81395 \times 10^{-8}$ \\
\hline 10 & 16.0 & 16.00000000 & 0 \\
\hline 11 & 14.2 & 14.19999999 & $7.04225 \times 10^{-8}$ \\
\hline 12 & 13.1 & 13.10000000 & 0 \\
\hline 13 & - & 13.50000000 & - \\
\hline 14 & 14.5 & 14.50000000 & 0 \\
\hline 15 & 15.0 & 15.00000000 & 0 \\
\hline 16 & 17.4 & 17.39999998 & $1.14943 \times 10^{-7}$ \\
\hline 17 & 16.5 & 16.50000000 & 0 \\
\hline 18 & 14.9 & 14.90000001 & $6.71141 \times 10^{-8}$ \\
\hline 19 & - & 14.01000000 & - \\
\hline 20 & 13.6 & 13.59999999 & $7.35294 \times 10^{-8}$ \\
\hline 21 & - & 15.30000001 & - \\
\hline 22 & - & 16.799999999 & - \\
\hline 23 & 17.8 & 17.80000000 & 0 \\
\hline 24 & - & 18.10000001 & - \\
\hline 25 & - & 18.00000000 & - \\
\hline 26 & 18.1 & 18.10000000 & 0 \\
\hline 27 & - & 18.70000000 & - \\
\hline 28 & 19.7 & 19.70000001 & $5.07614 \times 10^{-8}$ \\
\hline 29 & - & 20.80000001 & - \\
\hline 30 & 20.7 & 20.69999999 & $4.83092 \times 10^{-8}$ \\
\hline 31 & 18.5 & 18.50000000 & 0 \\
\hline
\end{tabular}


Terlihat bahwa nilai kadar hemoglobin yang diperoleh dari hasil solusi model menunjukkan bahwa terdapat 10 titik data yang berhasil dengan tepat diprediksi oleh model dengan konstanta solusi model masing-masing yaitu $R(0)=21.80000000, R(1)=18.00000000, R(10)=16.00000000$, $R(12)=13.10000000, R(14)=14.50000000, R(15)=15.00000000, R(17)=16.50000000, R(23)=$ $17.80000000, R(26)=18.10000000, R(31)=18.50000000$. Terdapat 9 titik data yang tidak dapat diprediksi dengan tepat namun memiliki kesalahan yang sangat kecil, dengan konstanta solusi model masing-masing yaitu $R(2)=16.80000001, \quad R(8)=18.19999999, \quad R(9)=17.20000001, \quad R(11)=$ $14.19999999, \quad R(16)=17.39999998, \quad R(18)=14.90000001, \quad R(20)=13.59999999, \quad R(28)=$ 19.70000001, $R(30)=20.69999999$. Terdapat pula 13 titik data yang diprediksi oleh model meskipun penderita PV tidak melakukan pengukuran laboratorium.

\section{KESIMPULAN}

Model matematika kadar hemoglobin penderita PV dalam bentuk persamaan differensial orde dua tak homogen dengan meninjau perubahan mood penderita PV menggunakan pencocokan kurva dengan metode interpolasi spline kubik berupa persamaan umum $\frac{d^{2} R}{d t^{2}}+\beta \cdot \frac{d R}{d t}+\omega^{2} \cdot R(t)=0.75 \sin 0.35 \pi t+u(t)$, dengan dengan $\frac{d^{2} R}{d t^{2}}$ berupa percepatan perubahan kadar

hemoglobin penderita PV per hari, $\frac{d R}{d t}$ berupa kecepatan perubahan kadar hemoglobin penderita PV per hari, $\beta$ berupa perubahan kadar estrogen per hari, $\omega^{2}$ berupa perubahan kadar serotonin per hari, $R(t)$ berupa kadar hemoglobin penderita PV pada hari ke-t. Sementara untuk ketepatan solusi model kadar hemoglobin penderita PV yang dibangun dengan data pengukuran laboratorium kadar hemoglobin penderita PV menunjukkan bahwa terdapat 10 titik data yang berhasil dengan tepat diprediksi oleh model. Dapat pula dilihat 9 titik data yang tidak dapat diprediksi dengan tepat namun memiliki kesalahan yang sangat kecil. Selain itu, terdapat pula 13 titik data yang diprediksi oleh model meskipun penderita PV tidak melakukan pengukuran hematologi. Sehingga dengan ketepatan solusi model yang dibangun dapat memperkirakan data kosong yaitu data yang sebelumnya tidak dimiliki dari pemeriksaan hematologi, dimana titik data ini merupakan hal penting untuk kelanjutan diagnosa lanjut PV.

\section{DAFTAR PUSTAKA}

[1]. Nursyahbani, A. dan Nuraini, N. 2009. Model Matematika Pengaruh Dinamika Perasaan Terhadap Pre-Menstruation Syndrome. FMIPA ITB. Bandung.

[2]. Supandiman, I. 1994. Hematologi Klinik. Edisi Pertama. Alumni. Bandung.

[3]. Wicaksono. 2013. Polisitemia. (http://emirzanurwicaksono.blog.unissula.ac.id), diakses 19 Oktober 2013. 